\title{
Phosphoglycerate Mutase Deficiency
}

National Cancer Institute

\section{Source}

National Cancer Institute. Phosphoglycerate Mutase Deficiency. NCI Thesaurus. Code C131647.

A rare, autosomal recessive, inherited disorder caused by mutation of the PGAM2 gene.

It is characterized by non-spherocytic hemolytic anemia, exercise-induced cramping,

myoglobinuria, and presence of tubular aggregates on muscle biopsy. 